\title{
Article
}

\section{Sustainable preparation of MIL-100(Fe) and its photocatalytic behavior in the degradation of methyl orange in water}

Kiros Guesh, Clarice Alves Dale Caiuby, Alvaro Mayoral, Manuel Diaz-Garcia, Isabel Díaz, and Manuel Sánchez-Sanchez

Cryst. Growth Des., Just Accepted Manuscript • Publication Date (Web): 27 Feb 2017

Downloaded from http://pubs.acs.org on February 27, 2017

\section{Just Accepted}

"Just Accepted" manuscripts have been peer-reviewed and accepted for publication. They are posted online prior to technical editing, formatting for publication and author proofing. The American Chemical Society provides "Just Accepted" as a free service to the research community to expedite the dissemination of scientific material as soon as possible after acceptance. "Just Accepted" manuscripts appear in full in PDF format accompanied by an HTML abstract. "Just Accepted" manuscripts have been fully peer reviewed, but should not be considered the official version of record. They are accessible to all readers and citable by the Digital Object Identifier (DOI®). "Just Accepted" is an optional service offered to authors. Therefore, the "Just Accepted" Web site may not include all articles that will be published in the journal. After a manuscript is technically edited and formatted, it will be removed from the "Just Accepted" Web site and published as an ASAP article. Note that technical editing may introduce minor changes to the manuscript text and/or graphics which could affect content, and all legal disclaimers and ethical guidelines that apply to the journal pertain. ACS cannot be held responsible for errors or consequences arising from the use of information contained in these "Just Accepted" manuscripts. 


\section{Sustainable preparation of MIL-100(Fe) and its photocatalytic behavior in the degradation of methyl orange in water}

Kiros Guesh, ${ }^{a}$ Clarice A. D. Caiuby, ${ }^{b}$ Álvaro Mayoral, ${ }^{c}$ Manuel Díaz-Garcia, ${ }^{b}$ Isabel Díaz, ${ }^{b}$ and Manuel Sanchez-Sanchez ${ }^{b, *}$

${ }^{a}$ Department of Chemistry, Aksum University, P.O.Box 1010, Ethiopia

${ }^{\mathrm{b}}$ Instituto de Catálisis y Petroleoquímica (ICP), CSIC, C/Marie Curie, 2, 28049 Madrid, Spain

${ }^{c}$ Laboratorio de Microscopías Avanzadas, Instituto de Nanociencia de Aragon, Universidad de Zaragoza, Spain.

ABSTRACT. The real industrial establishment of MOFs requires significant advances in economic and chemical sustainability. This work describes a novel and simple method to prepare one of the most widely studied MOF material, i.e. MIL-100(Fe), which significantly improves the sustainability of the conventional process in several aspects. Interestingly, the only difference in the preparation method of MIL-100(Fe) compared with that of semi-amorphous Fe-BTC (MOF material commercialized as Basolite F300 having the same metal and linker, and which can be also prepared under similar sustainable conditions), is to start from $\mathrm{Fe}$ (II) or $\mathrm{Fe}$ (III) sources, respectively, which opens certain versatility options in the room temperature synthesis procedures of MOF materials. The prepared samples were characterized using XRD, TGA, $\mathrm{N}_{2}$ adsorption/ desorption isotherms, Cs-aberration corrected STEM and UV-Vis DRS. These two room-temperature-made Fe-BTC materials were tested in the industrially-demanded photocatalytic degradation of methyl orange under both ultraviolet and solar light radiation. MIL-100(Fe) was a very active photocatalyst in comparison with its homologue. That difference was mainly attributed to the presence of larger cavities within its structure.

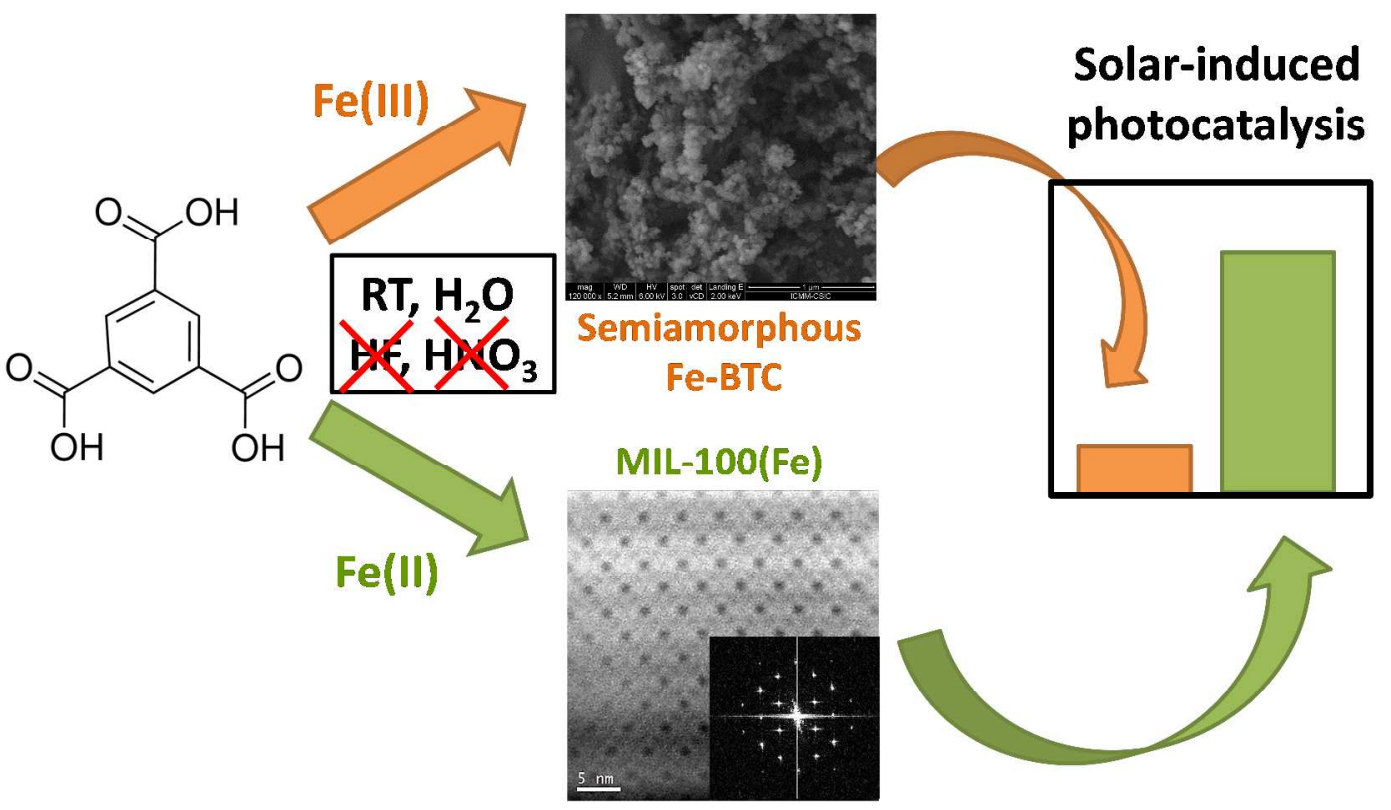

Dr. Manuel Sánchez-Sánchez

Instituto de Catálisis y Petroleoquímica, ICP-CSIC

C/ Marie Curie, 2, 28049 Madrid, Spain

Tel.: +34-915854795; Fax: +34-915854760

E-mail: manuel.sanchez@icp.csic.es 


\title{
Sustainable preparation of MIL-100(Fe) and its photocatalytic behavior in the degradation of methyl orange in water
}

\author{
Kiros Guesh, ${ }^{a, \#}$ Clarice A. D. Caiuby ${ }^{b, \#}$ Álvaro Mayoral, ${ }^{c}$ Manuel Díaz-García, ${ }^{b}$ Isabel Díaz, ${ }^{b}$ \\ and Manuel Sánchez-Sánchez ${ }^{b, *}$ \\ ${ }^{a}$ Department of Chemistry, Aksum University, P.O.Box 1010, Ethiopia \\ ${ }^{\mathrm{b}}$ Instituto de Catálisis y Petroleoquímica (ICP), CSIC, C/Marie Curie, 2, 28049 Madrid, Spain \\ ${ }^{\mathrm{c}}$ Laboratorio de Microscopías Avanzadas, Instituto de Nanociencia de Aragon, Universidad de \\ Zaragoza, Spain.
}

\# These two authors have contributed equally in this work. 


\begin{abstract}
The real industrial establishment of MOFs requires significant advances in economic and chemical sustainability. This work describes a novel and simple method to prepare one of the most widely studied MOF material, i.e. MIL-100(Fe), which significantly improves the sustainability of the conventional process in several aspects. This MOF material is prepared (i) at room temperature (instead of $150^{\circ} \mathrm{C}$ used in the conventional method), (ii) after a few hours (instead of 6 days), (iii) in the absence of any inorganic corrosive acid (significant amount of HF and $\mathrm{HNO}_{3}$ are used in the conventional method), and (iv) it is washed at room temperature (unlike the washing at $80^{\circ} \mathrm{C}$ for $3 \mathrm{~h}$ ). Interestingly, the only difference in the preparation method of MIL-100(Fe) compared with that of semi-amorphous Fe-BTC (MOF material commercialized as Basolite F300 having the same metal and linker, and which can be also prepared under similar sustainable conditions), is to start from Fe(II) or Fe(III) sources, respectively, which opens certain versatility options in the room temperature synthesis procedures of MOF materials. The prepared samples were characterized using XRD, TGA, $\mathrm{N}_{2}$ adsorption/ desorption isotherms, $\mathrm{C}_{\mathrm{s}^{-}}$ aberration corrected STEM and UV-Vis DRS. These two room-temperature-made Fe-BTC materials were tested in the industrially-demanded photocatalytic degradation of methyl orange under both ultraviolet and solar light radiation. MIL-100(Fe) was a very active photocatalyst in comparison with its homologue. That difference was mainly attributed to the presence of larger cavities within its structure.
\end{abstract}




\section{Introduction}

The versatility of Metal-Organic Frameworks (MOFs) does not only become extraordinarily wide in physico-chemical aspects such as porosity, structures and compositions. ${ }^{1}$ MOFs can be prepared by a variety of methodologies hardly reached by any other class of materials. ${ }^{2}$ That versatility should be explored and exploited in the current industrial context, which is (or at least should be) governed by economic and chemical sustainability. In this sense, sustainable procedures of the MOFs with potential applications and of suitable prices have started to be developed in the last few years. ${ }^{2-10}$

The ideal preparation of MOFs in a sustainable way would include room temperature, short synthesis times, the absence of solvents or the use of solvents as harmless and cheap as water, the non-generation of any harmful by-products, the absence of any corrosive reactants or avoiding long and/or aggressive post-synthesis washing or treatments to purify/activate the samples. Our group has patented ${ }^{11}$ and published $^{5,7}$ a procedure satisfying any of that desired premises, and it has been successfully applied to X-MIL-53(Al), ${ }^{5} \mathrm{Zn-MOF}-74^{5}$ and even it allowed the first reported direct preparation of the commercial semiamorphous Fe-BTC material. $^{7}$

The most conventional synthesis of MIL- $100(\mathrm{Fe})$ is carried out at $150{ }^{\circ} \mathrm{C}$ for 6 days in the presence of the environmentally harmful and corrosive acids $\mathrm{HF}$ and $\mathrm{HNO}_{3}$, which gives a mixture with $\mathrm{pH}$ below 1 , and the recovered solid should be washed at $80{ }^{\circ} \mathrm{C}$ in water for 3 hours. $^{12}$ Nevertheless, some works have already reported a bit more sustainable synthesis approaches, particularly trying to avoid the use of corrosive acids. ${ }^{13-15}$ Agostoni et al. prepared HF-free MIL-100 nano MOFs with 10 times higher yield than the conventional methods. However, the authors use microwave-assisted hydrothermal synthesis method, heating the 
starting mixture at $130{ }^{\circ} \mathrm{C}$ for 6 min. ${ }^{16}$ Recently, Zhang et al. synthesized MIL-100 (Fe) with HFfree via the reaction of ferric nitrate and trimesic acid by heating it at $95{ }^{\circ} \mathrm{C}$ for $12 \mathrm{~h} .{ }^{17,18}$ Despite these improvements to produce HF-free MIL-100(Fe) in an increasingly sustainable, to the best of our knowledge there are no reports that show room temperature synthesis of HF-free MIL$1(\mathrm{Fe})$.

The challenge of preparing MIL-100(Fe) under fully sustainable conditions becomes even greater considering that the preparation of the Basolite F300-like semiamorphous Fe-BTC material, which is formed with the same linker and the same metal and it is structurally ${ }^{7,15}$ and catalytically $^{19}$ related to MIL-100(Fe), has been already reported by applying this sustainable approaches, ${ }^{7}$ and therefore there is no evident room to change the temperature, the solvent or the absence of acids.

On the other hand, MIL-100(Fe) is a quite attractive MOF material for different applications due to several reasons including its mesoporous cavities, the reduced price of the linker and the metal source, the unsaturated metal centers with Lewis acid and redox properties, a non-apparent in vivo toxicity, etc. Amongst the different applications of MIL-100(Fe), its use as photocatalyst is probably the application that has awakened the highest interest in the very few last years. ${ }^{20-28}$ In general, MOF materials are being widely used as photocatalysts, ${ }^{24,}$ 29-34 in part due to their highly tunable band gap thanks to their huge compositional and structural versatility. ${ }^{33,35-41}$ Remarkably, MIL-100(Fe) by itself and/or supporting any species exalting its photocatalytic activity such as $\mathrm{Fe}_{3} \mathrm{O}_{4}, \mathrm{CdS}$ or metals, can become quite photoactive by irradiating it with visible light, which emphasizes the sustainability of the global (synthesis plus application) process. 
In this work, the most sustainable preparation ever reported of a high-quality MIL$100(\mathrm{Fe})$ material is described. The structure has been analyzed by several methods paying special attention to state-of-art electron microscopy which has allowed looking at the pore distribution as well as obtaining unit cell parameters. This material was photocatalytically tested in the degradation of methyl orange (MO) in aqueous solution under ultraviolet and completelysustainable outdoor solar light irradiation. Methyl orange is one of the most stable azo dyes which are extensively used in the textile industry and resistant to biodegradation.

\section{Experimental Details}

The experimental synthesis procedure is based on previous reported sustainable methods. ${ }^{5,7,11}$ A typical method, depicted in the top part of Scheme 1, starts with the preparation of two different solutions. Solution $1(\mathrm{pH} \sim 11)$ contains $1.676 \mathrm{~g}(7.6 \mathrm{mmol})$ of $\mathrm{H}_{3} \mathrm{BTC}$ dissolved in $23.72 \mathrm{~g}$ of $1 \mathrm{M} \mathrm{NaOH}$ aqueous solution $(22.8 \mathrm{mmol})$. Solution $2(\mathrm{pH} \sim 2.7)$ is prepared by dissolving $2.26 \mathrm{~g}(11.4 \mathrm{mmol})$ of $\mathrm{FeCl}_{2} \cdot 4 \mathrm{H}_{2} \mathrm{O}$ in $97.2 \mathrm{~g}$ of $\mathrm{H}_{2} \mathrm{O}$. After becoming complete clear solutions in both cases, Solution 1 was added dropwise over Solution 2 under stirring, giving a mixture with molar ratio $1.5 \mathrm{Fe}: 1.0 \mathrm{H}_{3} \mathrm{BTC}: 3.0 \mathrm{NaOH}: 880 \mathrm{H}_{2} \mathrm{O}$ whose $\mathrm{pH}$ was around 5.2. Time zero was taken when the addition of all Solution 1 over Solution 2 is finished. The stirring continued at room temperature for $24 \mathrm{~h}$, and some aliquots were taken off at different synthesis times. The solid was recovered by centrifugation at $3700 \mathrm{rpm}$, and then washing three times with water and one more time with ethanol. The sample was dried at room temperature. $4.01 \mathrm{~g}$ of powder (76\% yield) were collected, and it was labelled as MIL-100(Fe)-RT.

Basolite F300-like semiamorphous Fe-BTC material was prepared exactly following the procedure published elsewhere for such material $^{7}$ (bottom part of Scheme 1). A typical synthesis 
starts with the preparation of two solutions: (i) the colorless Solution $1(\mathrm{pH} \sim 11)$ was prepared by dissolving $0.263 \mathrm{~g}$ of trimesic acid $\left(\mathrm{H}_{3} \mathrm{BTC}\right)$ in $10.150 \mathrm{~g}$ of $1 \mathrm{M} \mathrm{NaOH}$ aqueous solution; and (ii) the yellowish orange Solution $2(\mathrm{pH} \sim 1.8)$ was prepared by dissolving $0.508 \mathrm{~g}$ of $\mathrm{FeCl}_{3} \cdot 6 \mathrm{H}_{2} \mathrm{O}$ in $10 \mathrm{~g}$ of $\mathrm{H}_{2} \mathrm{O}$. Next, Solution 2 was added dropwise over Solution 1 under magnetic stirring, generating the immediate appearance of a brownish orange solid. The resultant suspension $(\mathrm{pH} \sim 2.1)$ was maintained under stirring at room temperature $\left(23{ }^{\circ} \mathrm{C}\right)$ during ten minutes. The molar composition of the final mixture of both solution was exactly equal to that of the MIL-100(Fe) described above, i.e. $1.5 \mathrm{Fe}: 1.0 \mathrm{H}_{3} \mathrm{BTC}: 3.0 \mathrm{NaOH}: 880 \mathrm{H}_{2} \mathrm{O}$. The solids were recovered by centrifugation, washed different times with deionized water and subsequently with ethanol, and then dried at room temperature. For comparison purposes, Basolite F300, a commercial Fe-BTC material purchased from Sigma-Aldrich, and commercial $\mathrm{Fe}_{2} \mathrm{O}_{3}$, were also used. Both materials were used as-received, with no further treatment.

X-ray diffraction (XRD) patterns were collected with an X'Pert Pro PANalytical diffractometer $\left(\mathrm{CuK}_{\alpha 1}\right.$ radiation $\left.=0.15406 \mathrm{~nm}\right)$. Thermogravimetry (TGA) analyses of the samples were registered on a Perkin-Elmer TGA7 equipment in a temperature range of 25-900 ${ }^{\circ} \mathrm{C}$ with a heating rate of $20^{\circ} \mathrm{C} / \mathrm{min}$ under air flow. Nitrogen adsorption and desorption isotherms were measured in a Micromeritics ASAP 2420 physisorption analyzer; all the samples were degassed at $150{ }^{\circ} \mathrm{C}$ for $16 \mathrm{~h}$ under high vacuum prior to data collection.

Spherical aberration $\left(\mathrm{C}_{\mathrm{s}}\right)$ corrected Scanning Transmission Electron Microscopy (STEM) coupled with an Annular Dark Field Detector (ADF) was employed for the materials characterization. Prior observation the samples were deeply crushed using a mortar and pestle and dispersed in ethanol. STEM observations were performed in a probe corrected TITAN XFEG transmission electron microscope operated at $300 \mathrm{kV}$. The microscope is equipped with a 
monochromator for the electron gun, which was not excited for the current experiments, and EDS EDAX detector and a Tridiem Gatan energy Filter for chemical analyses. The electron microscopy Multislice STEM simulations were performed using QSTEM software (C. T. Koch, Arizona State University 2002) along the [110] orientation. The dynamic scattering simulation is based on the multislice method; the parameters used were: $C s=-500 \mathrm{~nm}$, Uacc $=300 \mathrm{kV}$, an ADF collection angle was set to be between 30 and $160 \mathrm{mrad}$ and a convergence semiangle of 17.5 mrad. The beam size was set to be $2.5 \AA$. The beam current used for imaging the structures was usually kept under $8 \mathrm{pA}$, and the exposure time varied from $6 \mu$ s up to $12 \mu$ s per pixel in a 1024 $\times 1024$ pixels images. UV-Vis Diffuse Reflectance Spectroscopy (DRS) measurements were run in a Varian Cary 5000 double-beam UV-Vis-NIR spectrophotometer. Collected spectra were converted to Kubelka-Munk function, F(R) versus wavelength.

For a particular photocatalytic test, $0.25 \mathrm{~g}$ of sample was suspended in a $750 \mathrm{~mL} 5 \mathrm{ppm}$ aqueous solution of methyl orange (MO) in a quartz glass reactor equipped with quartz glass cooling pipe and ports for sample withdrawing and oxygen purging. The mixture was stirred for $1 \mathrm{~h}$ in continuous purging of air to maintain adsorption/ desorption equilibrium of MO with the powder photocatalyst material. Then, the suspension was irradiated with a $150 \mathrm{~W}$ UV lamp (Heraeus medium pressure mercury lamp) and samples were withdrawn in time intervals for analysis after filtering out the photocatalyst. In the case of outdoor test, the mixture in a beaker was stirred in dark for $1 \mathrm{~h}$ and exposed to solar light in an open air from 10:00 am to 4:00 pm in Addis Ababa, Ethiopia. It was sunny at an average temperature maximum of $24{ }^{\circ} \mathrm{C}$. The withdrawn samples were analyzed in PerkinElmer Lambda $950 \mathrm{UV}-$ Vis spectrophotometer. The spectra of the samples were recorded from 800 to $200 \mathrm{~nm}$. 


\section{Results and Discussion}

The beginning of this section describes the kinetics of the sustainable preparation of the MIL-100(Fe) materials, as well as a detailed characterization of the resultant material. In a highly-related precedent ${ }^{7}$, the formation of the semi-amorphous Basolite F300-like Fe-BTC material under similar conditions, a solid was instantaneously formed once linker and metal solutions were mixed (bottom of Scheme 1). Indeed, the shorter synthesis time, the better is the quality of the resultant MOF material, at least in terms of intercrystalline mesoporosity and, consequently, of catalytic activity in the oxidation of cyclohexene. ${ }^{7}$ Figure 1 shows the XRD patterns of the Fe-BTC extracted from the synthesis mixture of MIL-100(Fe) system after different synthesis times once Solution 1 (linker $\mathrm{BTC}^{3-}$ solution) is added over Solution 2 (iron solution). Unlike the synthesis of the semiamorphous Fe-BTC, ${ }^{7}$ the immediately formed precipitate after mixing both solutions is not brownish orange, as expected for a Fe(III)-BTC material like MIL-100(Fe), but light green, which is the typical color of Fe(II) compounds, quite similar to the color of the iron source $\mathrm{FeCl}_{2}$ (Scheme 1). It is expected that the starting $\mathrm{Fe}$ (II) is slowly oxidized to $\mathrm{Fe}(\mathrm{III})$ as an essential requirement to form MIL-100(Fe). At this point, it is noteworthy that the conventional preparation of the MIL-100(Fe) also implies the oxidation of the iron source, from $\mathrm{Fe}^{0}$ to $\mathrm{Fe}(\mathrm{III}) .^{12}$ Unexpectedly, the still-green sample extracted at the first studied time $(1 \mathrm{~h})$ is basically composed by the phase MIL-100(Fe), which prevails in every difractogram of Figure 1. Apart from this dominant phase, some other phases are detected in the diffractograms of the samples extracted after the shortest tested synthesis times. The most evident XRD peak that does not belong to the phase MIL- $100(\mathrm{Fe})$ is found in the $9-10^{\circ} 2 \theta$ range (marked with arrows in Fig. 1). It did not either match with other previously-published crystalline Fe(III)-BTC (MIL-65) ${ }^{42}$ or Fe(II)-BTC (MIL-45). ${ }^{43}$ The intensity of that peak 
systematically decreases with synthesis time, not being detected after 4 hours. By then, the samples are brownish orange and MIL-100(Fe) is the only observed phase. Prolonged times improves the crystallinity of the MIL-100(Fe) samples, at least up to $24 \mathrm{~h}$. The sample collected after $24 \mathrm{~h}$ will be used for further characterization comparison in this study, and it will be denoted as MIL-100(Fe)-RT.

In order to certify that the dominant phase detected in the diffractograms of Figure 1 is MIL-100(Fe), an exhaustive comparison of the experimental powder XRD pattern of the sample MIL-100(Fe)-RT after 24 hours with a simulated XRD pattern from the CIF file of the MIL$100(\mathrm{Fe})$, was carried out. ${ }^{12}$ Figure 2 shows such comparison in two $2 \theta$ ranges: at low angle $2 \theta$, from 1 to $6^{\circ}$ (Figure 2a), and at high angle $2 \theta$ (Figure $2 \mathrm{~b}$ ). The agreement between both patterns is excellent, leaving little room for any doubt in the phase identification. Every single expected peak of the XRD pattern simulated from the cif file of MIL-100(Fe) ${ }^{12}$ is present in the experimental XRD patterns with similar relative intensity, and there is not any other single detected XRD peak.

Figure 2 also shows the XRD pattern of the sample Fe-BTC that is similar to the commercially available Basolite F300. That sample is denoted as Fe-BTC-RT in this work. Their broad XRD peaks indicate the semi-amorphous nature of this Fe-BTC sample. Moreover, the $2 \theta$ positions of these broad XRD peaks match very well with any accumulation of the narrow peaks of the pattern of the sample MIL-100(Fe), as described elsewhere, ${ }^{15}$ including the broad peak centered at $c a .4^{\mathrm{o}}{ }^{7}$ which has been attributed to the structural similarities between both Fe-BTC materials. ${ }^{7,15,19}$ Beyond such structural similarities, it must be highlighted that both Fe-BTC materials are alike in terms of composition, as they are formed by the same organic linker $\left(\mathrm{BTC}^{3-}\right.$ ) and the same metal $(\mathrm{Fe})$ in the same oxidation state $(3+)$. Moreover, these two particular 
materials have been prepared under equal sustainable conditions: room temperature, short synthesis times, water as unique solvent, in the absence of any corrosive acid, room temperature washing, etc., and the only distinction causing the formation of either semi-amorphous Fe-BTC or MIL-100(Fe) is the oxidation state of the starting source, $\mathrm{Fe}^{3+}$ or $\mathrm{Fe}^{2+}$, respectively, both having also the same counter-anion (chloride). Therefore, the change in the oxidation state of the starting metal source has somehow a structure-directing effect, which is important in a scarcely versatile system.

To confirm the structural nature of both Fe-BTC materials prepared at room temperature, the samples MIL-100(Fe)-RT and Fe-BTC-RT were exhaustively studied by advanced Transmission Electron Microscopy techniques. Due to the high sensitivity of this kind of materials under the electron beam, their structures usually collapse within seconds of irradiation. With the intention of acquiring images of their porous frameworks with maximum possible resolution low-dose conditions are imperative. ${ }^{44}$ The spherical aberration corrected images were collected using a dose usually below 4 pA, using a dwell time of $6 \mu$ s per pixel, with a total number of pixels per image of $1024 \times 1024$. These experimental conditions have been previously described for similar materials and they have also been successfully applied for the observation of highly unstable ordered porous solids. ${ }^{45}$ Although low voltages have been used in the analysis of mesoporous materials ${ }^{46}$ and even with metal organic frameworks, ${ }^{47}$ a careful control of the electron dose have been found to be the most critical factor in order to minimize the effect of the electron beam damage. The low magnification image, Figure 3a reveals that the MIL-100(Fe)RT crystallizes in form of faceted particles of $500 \mathrm{~nm}$ up to $1 \mu \mathrm{m}$. Figure $3 \mathrm{~b}$ allows the visualization of the pore distribution of a crystal along the [110] orientation. The FFT shown inset confirms that crystal orientation and it can be indexed assuming $F d-3 m$ with a unit cell of a 
$=70.74 \AA$. The reported unit cell parameter for MIL-100(Fe) with this spatial group is $73.34 \AA$, although it is well-known that there is certain underestimation of unit cell parameters by TEM compared with XRD. ${ }^{45,48,49}$ From the Fourier transform it can be identified a diffraction spot situated at $1.25 \mathrm{~nm}^{-1}$ that corresponds to the 5-5-5 reflection representing $7.9 \AA$ image resolution. A closer observation is depicted in Figure 3c, that for better clarity it was Fourier filtered. Due to the large number of atoms forming the unit cell that makes MIL-100(Fe)-RT a highly complex material, obtaining atomic resolution data results tremendously complex. Further confirmation of the structure was corroborated and lattice constants were acquired from tilting along different orientations (see Figures S1 and S2) where the crystals orientated along the [211] and the [111] projections are shown. Image simulations were also performed along the [110] orientation observing a clear agreement between experimental and simulated data (Figure $3 \mathrm{c}$ inset).

The material prepared using $\mathrm{Fe}(\mathrm{III})$ as the metal source, Fe-BTC-RT, yielded a significantly lower crystallinity material as most of the particles analyzed exhibited amorphous nature. Only one crystal could be imaged observing the same structure of MIL-100 in this case. Figure S3 depicts the observation of a crystalline particle of Fe-BTC-RT along the [110] orientation revealing the similarities with MIL-100(Fe)-RT except that a small contraction of the unit cell from $70.74 \AA$ to $67.76 \AA$ was detected.

Apart from the structural characterization, different techniques have been applied to evaluate the quality of the MIL-100(Fe) prepared under the above-mentioned sustainable conditions. Just like in Figure 2, the sample MIL-100(Fe)-RT prepared after 24 hours of synthesis reaction was taken as representative of the sustainable MIL-100(Fe) materials. Figure 4 shows the TGA profile of such sample compared with these of the free linker $\mathrm{H}_{3} \mathrm{BTC}$ and the semi-amorphous sample Fe-BTC. The TGA profile of the sample MIL-100(Fe)-RT is similar to 
that of the samples prepared under the conventional conditions ${ }^{12}$ in three key aspects: (i) the decomposition pattern followed by the organic linker, which is abrupt and in practically one single step, contrasting to the two quite different steps found in the TGA profile of the sample Fe-BTC-RT and the free linker $\mathrm{H}_{3} \mathrm{BTC}$; (ii) the temperature values of the main linker losses, which were centered at 403,383 and $346{ }^{\circ} \mathrm{C}$ for the conventional MIL-100(Fe), MIL-100(Fe)-RT and Fe-BTC-RT samples, respectively; and (iii) the linker loss/residual weight ratios were also similar for both MIL-100(Fe) samples (1.53 for conventional and 1.68 for the RT one) and quite different from that of the Fe-BTC-RT sample (2.22), which therefore has an excess of organic linker. In this context, it is worth mentioning that the Fe-BTC-RT sample is prepared under $\mathrm{pH}$ value (around 2.0) at which the protonated form $\mathrm{H}_{3} \mathrm{BTC}$ of the linker should be the dominant specie. Nevertheless, it could not be detected by XRD. The small differences found between the TGA profiles of conventional MIL-100(Fe) and MIL-100(Fe)-RT could be related to the presence of $\mathrm{F}^{-}$ions in the final structure of the conventional one, ${ }^{12}$ which are substituted by $\mathrm{OH}^{-}$ ions in its homologous sample prepared at room temperature.

Figure 5a shows the $\mathrm{N}_{2}$ adsorption/desorption isotherms of the four Fe-BTC samples: a conventionally-prepared MIL-100(Fe), the two samples prepared room temperature MIL100(Fe)-RT and Fe-BTC-RT, and the commercial Basolite F300. Both the conventional MIL100(Fe) and MIL-100(Fe)-RT revealed an adsorption isotherm profile characteristic of microporous solids. However, due to the presence of two types of microporous windows and mesoporous cages with different sizes, two secondary uptakes at $c a . \mathrm{p} / \mathrm{p}_{0}=0.06$ and 0.12 can be distinguished from the isotherm. These features are more evident in the BJH pore size distribution curves (Figure 5b, Table 1), as two peaks at 1.84 and $2.23 \mathrm{~nm}$ are found. These values are $\sim 0.7 \mathrm{~nm}$ lower than the diameter of the supercages, 2.5 and $2.9 \mathrm{~nm},{ }^{12}$ because of the 
well-known tendency of $\mathrm{BJH}$ method to underestimate the value of the mesoporous, as it was discussed elsewhere for these Fe-BTC materials. ${ }^{7}$ The semiamorphous Fe-BTC materials only possess the smallest supercage present in MIL-100(Fe), which explains the lower surface area and pore volume. The estimated surface area of the sample MIL-100(Fe)-RT prepared at room temperature $\left(1974 \mathrm{~m}^{2} / \mathrm{g}\right.$ by BET method, $2662 \mathrm{~m}^{2} / \mathrm{g}$ by Langmuir method) is quite close to those of the conventional MIL-100(Fe) prepared in this work (2028 and $2834 \mathrm{~m}^{2} / \mathrm{g}$, respectively) and the reported one. ${ }^{12}$ On the other hand, the textural properties of the semi-amorphous sample FeBTC-RT prepared at room temperature starting from Fe(III) source, surpass these of the commercial Fe-BTC, due to the presence of higher external surface in the former. Indeed, the difference is even greater in terms of pore volume (Table 1).

The diffuse reflectance UV-vis (DR-UV-vis) spectra of the two Fe-BTC samples prepared at room temperature are shown in Figure 6. As expected, the spectra of both samples are quite similar in position and broadening. However, they are also a bit different. In the UV region, the spectrum of MIL-100(Fe)-RT seems to possess two overlapped bands, whereas the spectrum of the sample Fe-BTC-RT only has one of them. Although it is tempting to attribute the two bands to the two different mesoscopic cages found in MIL-100(Fe) and the unique band in the spectrum of the semiamorphous Fe-BTC material to unique kind of cavities found in this MOF, further studies will be necessary to either support or deny this interpretation. On the other hand, it is clear that the samples are semiconducting MOF with estimated band gap energy of 3.08 and $3.19 \mathrm{eV}$ for MIL-100(Fe)-RT and Fe-BTC-RT, respectively (Figure S4). It is worthwhile to underline that the band gap of the commercial $\mathrm{TiO}_{2}$ known as $\mathrm{P} 25$, the perexcellence commercial photocatalyst, is $\sim 3.0 \mathrm{eV}$. On the other hand, the spectra show certain absorbance in visible light in good agreement to the brownish orange color of the samples. 
Nevertheless, the intensity of the absorption bands at the visible region is very small, and it is presumed that low number of photons, which has paramount significance in photocatalysis, is adsorbed. However, still this material could be good photocatalyst under the solar radiation since there is some UV ratio in the solar light.

Photocatalytic activity of Fe-based MOFs in general and conventional MIL-100(Fe) in particular has been reported in the literature. ${ }^{24,28,34}$ In this study, MIL-100(Fe)-RT and Fe-BTCRT photocatalysts were tested in the degradation of 5 ppm MO (methyl orange). A commercial $\mathrm{Fe}_{2} \mathrm{O}_{3}$ was also tested under the same conditions for comparison purposes. It must be remarked that, irrespective of the oxidation state of the iron source in the synthesis, both Fe-BTC materials contains Fe(III) in their structure, as MIL-100 structure is only formed with trivalent metal ions. Figure 7 shows the photocatalytic degradation of MO on these samples. In the presence of the sample MIL-100(Fe)-RT, $64 \%$ of 5 ppm MO has been photocatalytically degraded under irradiation of UV light for $7 \mathrm{~h}$ whereas $40 \%$ of $5 \mathrm{ppm}$ MO was degraded under solar light irradiation (outdoor experiment). The higher photocatalytic activity under UV irradiation than the outdoor experiment is due to the higher intensity of the UV light than the solar light and the higher absorption coefficient of the sample in the UV region than in the visible region (Figure 6). High intensity of light enables the system to produce higher number of electron/hole pairs which in turn, facilitates the photocatalytic degradation and redox reaction of the system. To reveal whether the MIL-100(Fe)-RT is a good candidate as photocatalyst, it was compared with its counterpart oxide $\mathrm{Fe}_{2} \mathrm{O}_{3}$ under the same experimental conditions. As it is plotted in Figure 7, the pure oxide degraded only $18 \%$ of the MO, thus the higher photocatalytic activity of MIL100(Fe)-RT could be attributed to higher adsorption capacity of the MOF owing to its higher specific surface area reaching $1974 \mathrm{~m}^{2} \mathrm{~g}^{-1}$ according to BET method (Table 1). Similarly, the 
photocatalytic activity of Fe-BTC-RT was tested in the photocatalytic degradation of MO under similar experimental conditions as in MIL-100(Fe)-RT. However, no significant photocatalytic degradation of MO was recorded within $7 \mathrm{~h}$ reaction time. As it has been observed by XRD and $\mathrm{C}_{\mathrm{s}}$-STEM, these two samples show structural and compositional similarities, and have been prepared under equal sustainable conditions. Thus, the oxidation state of the starting source, $\mathrm{Fe}^{3+}$ or $\mathrm{Fe}^{2+}$, not only affects the crystallinity of the materials as in Figure 2 but also the photocatalytic activity toward degradation of MO. Even assuming that the surface area of Fe-BTC-RT is quite lower than that of MIL-100(Fe)-RT (Table 1), the reason behind the so different photocatalytic behavior must be found in other aspects, either in the different accessibility of the dye to the active centers or in the different intrinsic behavior of the centers. At this point, it must be stressed that the difference in terms of types of supercages between the structurally well-known MIL-100(Fe) material and their homologous semiamorphous Fe-BTC is that the latter only contains the smallest cages ${ }^{7}$ (Figure 4b) (cage diameter of $25 \AA$ with window entrance of $4.8 \mathrm{x}$ $5.8 \AA$ ) of the two types of cages found in MIL-100(Fe), which additionally have cages with diameter of $29 \AA$ and windows entrance of $8.6 \AA$. Considering that the dimensions of the MO molecule are $16.7 \times 6.1 \times 5.2 \AA,^{50}$ it is presumed that the dye will adsorb into MIL-100(Fe) but not in the Fe-BTC-RT sample. If so, it can be explained the notable photocatalytic activity of the MIL-100(Fe)-RT sample as well as the almost negligible one of the Basolite F300-like Fe-BTC material. However, not much can be said about the difference of the intrinsic photocatalytic activity of the iron centers composing these materials. Supporting such interpretation of the (in)accessibility of MO within Fe-BTC materials, Fe centers of the Fe-BTC-RT showed good activity in the oxidation of cyclohexene, ${ }^{7}$ which is a reactant able to diffuse in the cages of that material. 


\section{Conclusion}

A sustainable and easy method to prepare a high-quality MIL-100(Fe) material, one of the most widely investigated MOFs, is described. In contrast to the synthesis of the conventional MIL$100(\mathrm{Fe})$, this novel method is carried out at room temperature, in a few hours, in the total absence of any corrosive inorganic acids, and it does not require any post-synthesis washing treatment at high temperature. In addition, both the conventional and the new methods are carried out in water as the unique solvent. That synthesis could be reached by adding a base $(\mathrm{NaOH})$ as deprotonating agent of the linker. The only experimental difference with respect to the synthesis of the semiamorphous Basolite-F300-like Fe-BTC materials, also prepared under similar sustainable conditions, was the use of Fe(II) salts instead of Fe(III) ones as iron sources. Therefore, the oxidation state of metal source is a possible parameter for introducing versatility in MOFs prepared at room temperature, which is more limited than the solvothermal methods. In order to emphasize the sustainability of this method, the two Fe-BTC materials prepared at room temperature were tested as photocatalysts in the decomposition of the dye methyl orange, also at room temperature. The photocatalytic activity of the MIL-100(Fe) under both the UV light irradiation and outdoor photocatalytic activities were notable while the semiamorphous Fe-BTC shows no photocatalytic activity. The results were explained as a function of size of the supercages, as methyl orange can only fit in the MIL-100(Fe) material and not in the semiamorphous one. 


\section{Acknowledgements}

A.M. acknowledges European Union Seventh Framework Programme under GrantAgreement 312483 - ESTEEM2 (Integrated Infrastructure Initiative-I3). CC acknowledges Science without borders - CNPq - Brazil. KG and ID also acknowledge CSIC for Development program ICOOP-2014 COOPB20082 project number. This work has been (partially) financed by the Spanish State Research Agency (Agencia Española de Investigación, AEI) and the European Regional Development Fund (Fondo Europeo de Desarrollo Regional, FEDER) through the Project MAT2016-77496-R (AEI/FEDER, UE).

\section{References}

(1) Furukawa, H.; Cordova, K. E.; O'Keeffe, M.; Yaghi, O. M. Science 2013, 341, 1230444.

(2) Stock, N.; Biswas, S. Chem. Rev. 2012, 112, 933-969.

(3) Bayliss, P. A.; Ibarra, I. A.; Pérez, E.; Yang, S.; Tang, C. C.; Poliakoff, M.; Schröder, M. Green Chem. 2014, 16, 3796-3802.

(4) Ibarra, I. A.; Bayliss, P. A.; Perez, E.; Yang, S.; Blake, A. J.; Nowell, H.; Allan, D. R.;

Poliakoff, M.; Schröder, M. Green Chem. 2012, 14, 117-122.

(5) Sanchez-Sanchez, M.; Getachew, N.; Diaz, K.; Diaz-Garcia, M.; Chebude, Y.; Diaz, I. Green Chem. 2015, 17, 1500-1509.

(6) Getachew, N.; Chebude, Y.; Diaz, I.; Sanchez-Sanchez, M. J. Porous Mater. 2014, 21, 769-773.

(7) Sanchez-Sanchez, M.; de Asua, I.; Ruano, D.; Diaz, K. Cryst. Growth Des. 2015, 15 , 4498-4506.

(8) Shieh, F. K.; Wang, S. C.; Leo, S. Y.; Wu, K. C. Chem. Eur. J. 2013, 19, 11139-11142. 
(9) Klimakow, M.; Klobes, P.; Thünemann, A. F.; Rademann, K.; Emmerling, F. Chem. Mater. 2010, 22, 5216-5221.

(10) Cattaneo, D.; Warrender, S. J.; Duncan, M. J.; Castledine, R.; Parkinson, N.; Haley, I.; Morris, R. E. Dalton Trans. 2015, 45, 618-629.

(11) Sanchez Sánchez, M.; Díaz, I.; Getachew, N.; Chebude, Y. ES Patent 2012, P201231968.

(12) Horcajada, P.; Surble, S.; Serre, C.; Hong, D. Y.; Seo, Y. K.; Chang, J. S.; Greneche, J. M.; Margiolaki, I.; Ferey, G. Chem. Commun. 2007, 27, 2820-2822.

(13) García Márquez, A.; Demessence, A.; Platero-Prats, A. E.; Heurtaux, D.; Horcajada, P.; Serre, C.; Chang, J.-S.; Férey, G.; de la Peña-O'Shea, V. A.; Boissière, C.; Grosso, D.; Sanchez, C. Eur. J. Inorg. Chem. 2012, 32, 5165-5174.

(14) Canioni, R.; Roch-Marchal, C.; Sécheresse, F.; Horcajada, P.; Serre, C.; Hardi-Dan, M.; Férey, G.; Grenèche, J.-M.; Lefebvre, F.; Chang, J.-S.; Hwang, Y.-K.; Lebedev, O.; Turner, S.; Van Tendeloo, G. J. Mater. Chem. 2011, 21, 1226-1233.

(15) Seo, Y.-K.; Yoon, J. W.; Lee, J. S.; Lee, U. H.; Hwang, Y. K.; Jun, C.-H.; Horcajada, P.; Serre, C.; Chang, J.-S. Microporous Mesoporous Mater. 2012, 157, 137-145.

(16) Agostoni, V.; Horcajada, P.; Rodriguez-Ruiz, V.; Willaime, H.; Couvreur, P.; Serre, C.; Gref, R., Green Mater. 2013, 1, 209-217.

( 17) Zhang, F. M.; Jin, Y.; Shi, J.; Zhong, Y. J.; Zhu, W. D.; El-Shall, M. S., Chem. Eng. J. 2015, 269, 236-244.

(18) Zhang, F. M.; Shi, J.; Jin, Y.; Fu, Y. H.; Zhong, Y. J.; Zhu, W. D., Chem. Eng. J. 2015, 259, 183-190.

(19) Dhakshinamoorthy, A.; Alvaro, M.; Horcajada, P.; Gibson, E.; Vishnuvarthan, M.;

Vimont, A.; Grenèche, J.-M.; Serre, C.; Daturi, M.; Garcia, H. ACS Catal. 2012, 2, 2060-2065. 
(20) Zhang, C. F.; Qiu, L. G.; Ke, F.; Zhu, Y. J.; Yuan, Y. P.; Xu, G. S.; Jiang, X. J. Mater. Chem. A 2013, 1, 14329-14334.

(21) He, J.; Yang, H. Y.; Chen, Y. J.; Yan, Z. Y.; Zeng, Y. B.; Luo, Z. G.; Gao, W. Y.; Wang, J. Q. Water Air Soil Poll. 2015, 226, 197.

(22) Ke, F.; Wang, L. H.; Zhu, J. F. Nano Res. 2015, 8, 1834-1846.

(23) Liang, R. W.; Chen, R.; Jing, F. F.; Qin, N.; Wu, L. Dalton Trans. 2015, 44, (41), $18227-$ 18236.

(24) Liang, R. W.; Jing, F. F.; Shen, L. J.; Qin, N.; Wu, L. Nano Res. 2015, 8, 3237-3249.

(25) Liang, R. W.; Luo, S. G.; Jing, F. F.; Shen, L. J.; Qin, N.; Wu, L. Appl. Catal. B-Environ. 2015, 176, 240-248.

(26) Lv, H. L.; Zhao, H. Y.; Cao, T. C.; Qian, L.; Wang, Y. B.; Zhao, G. H. J. Mol. Catal. AChem. 2015, 400, 81-89.

(27) Zhao, H. Y.; Qian, L.; Lv, H. L.; Wang, Y. B.; Zhao, G. H. ChemCatChem 2015, 7, 4148-4155.

(28) Wang, D. K.; Wang, M. T.; Li, Z. H. ACS Catal. 2015, 5, 6852-6857.

(29) Zhang, T.; Lin, W. Chem. Soc. Rev. 2014, 43, 5982-93.

(30) Zhang, S.; Li, L.; Zhao, S.; Sun, Z.; Luo, J. Inorg. Chem. 2015, 54, 8375-8379.

(31) Laurier, K. G.; Vermoortele, F.; Ameloot, R.; De Vos, D. E.; Hofkens, J.; Roeffaers, M. B. J. Am. Chem. Soc. 2013, 135, 14488-14891.

(32) Gomes Silva, C.; Luz, I.; Llabres i Xamena, F. X.; Corma, A.; Garcia, H. Chem. Eur. J. 2010, 16, 11133-11138.

(33) Gascon, J.; Hernandez-Alonso, M. D.; Almeida, A. R.; van Klink, G. P.; Kapteijn, F.; Mul, G. ChemSusChem 2008, 1, 981-983. 
(34) Wang, D.; Huang, R.; Liu, W.; Sun, D.; Li, Z. ACS Catal. 2014, 4, 4254-4260.

(35) Ling, S.; Slater, B. J. Phys. Chem. C 2015, 119, 16667-16677.

(36) Yang, L.-M.; Fang, G.-Y.; Ma, J.; Ganz, E.; Han, S. S. Cryst. Growth Des. 2014, 14, 2532-2541.

(37) Lin, C. K.; Zhao, D.; Gao, W. Y.; Yang, Z.; Ye, J.; Xu, T.; Ge, Q.; Ma, S.; Liu, D. J. Inorg. Chem. 2012, 51, 9039-9044.

(38) Flage-Larsen, E.; Thorshaug, K.. Inorg. Chem. 2014, 53, 2569-2572.

(39) Flage-Larsen, E.; Røyset, A.; Cavka, J. H.; Thorshaug, K., J. Phys. Chem. C 2013, 117 , 20610-20616.

(40) Choi, J. H.; Choi, Y. J.; Lee, J. W.; Shin, W. H.; Kang, J. K. Phys. Chem. Chem. Phys. 2009, 11, 628-631.

(41) Botas, J. A.; Calleja, G.; Sanchez-Sanchez, M.; Orcajo, M. G. Int. J. Hydrogen Energy 2011, 36, 10834-10844.

(42) Riou-Cavellec, M.; Ferey, G., Solid State Sci. 2002, 4, 1221-1225.

(43) Riou-Cavellec, M.; Albinet, C.; Livage, C.; Guillou, N.; Nogues, A.; Greneche, J. M.; Ferey, G., Solid State Sci. 2002, 4, 267-270.

(44) Díaz, I.; Mayoral, A. Micron 2011, 42, 512-527.

(45) Mayoral, A.; Sanchez-Sanchez, M.; Alfayate, A.; Perez-Pariente, J.; Diaz, I. ChemCatChem 2015, 7, 3719-3724.

(46) Mayoral, A.; Arenal, R.; Gascon, V.; Marquez-Alvarez, C.; Blanco, R. M.; Diaz, I. ChemCatChem 2013, 5, 903-909.

(47) Díaz-García, M.; Mayoral, Á.; Díaz, I.; Sánchez-Sánchez, M. Cryst. Growth Des. 2014, $14,2479-2487$. 
(48) Deng, H.; Grunder, S.; Cordova, K. E.; Valente, C.; Furukawa, H.; Hmadeh, M.;

Gandara, F.; Whalley, A. C.; Liu, Z.; Asahina, S.; Kazumori, H.; O'Keeffe, M.; Terasaki, O.;

Stoddart, J. F.; Yaghi, O. M. Science 2012, 336, 1018-1023.

(49) Hudson, S.; Tanner, D. A.; Redington, W.; Magner, E.; Hodnett, K.; Nakahara, S. Phys.

Chem. Chem. Phys. 2006, 8, 3467-3474.

(50) Costantino, U.; Coletti, N.; Nocchetti, M.; Aloisi, G. G.; Elisei, F. Langmuir 1999, 15, 4454-4460.

\section{AUTHOR INFORMATION}

\section{Corresponding Author}

* Dr. Manuel Sanchez-Sanchez, Telephone: +34-915854795, Fax: +34-915854760, E-mail address: manuel.sanchez@icp.csic.es

\# These two authors have contributed equally in this work.

\section{Author Contributions}

The manuscript was written through contributions of all authors. All authors have given approval to the final version of the manuscript. 
Tables

Table 1. Textural properties of the two Fe-BTC samples prepared at room temperature. The textural values of a conventional MIL-100(Fe) and the commercial Basolite F300 are also given for comparison purposes.

\begin{tabular}{|c|c|c|c|c|}
\hline Sample & $\mathbf{S}_{\text {BET }}\left(\mathbf{m}^{\mathbf{2}} \mathbf{g}^{-\mathbf{1}}\right)$ & $\mathbf{E x t}_{\mathbf{~}} \mathbf{S}_{\mathbf{B E T}}\left(\mathbf{m}^{\mathbf{2}} \mathbf{g}^{\mathbf{- 1}}\right)^{\mathbf{a}}$ & $\mathbf{V}_{\mathbf{p}}\left(\mathbf{c m}^{\mathbf{3}} \mathbf{g}^{-\mathbf{1}}\right)^{\mathbf{b}}$ & PSD peaks (nm) $^{\mathbf{c}}$ \\
\hline MIL-100(Fe) & 2028 & 128 & 0.82 & $1.84,2.23$ \\
\hline MIL-100(Fe)-RT & 1974 & 117 & 0.75 & $1.85,2.26$ \\
\hline Fe-BTC-RT & 925 & 204 & 0.65 & 1.85 \\
\hline Basolite F300 & 885 & 72 & 0.40 & 1.81 \\
\hline
\end{tabular}

${ }^{\text {a }}$ Data from t-plot. External $\mathrm{S}_{\mathrm{BET}}$ is the difference between the total $\mathrm{S}_{\mathrm{BET}}$ and the microporous $\mathrm{S}_{\mathrm{BET}}{ }^{\mathrm{b}}$ Pore volume measured at $\mathrm{p} / \mathrm{p}_{0}=0.98 .{ }^{\mathrm{c}}$ Maxima of the peaks found in pore size distribution by the applying BJH method to the adsorption branches. 


\section{Schemes and Figures}
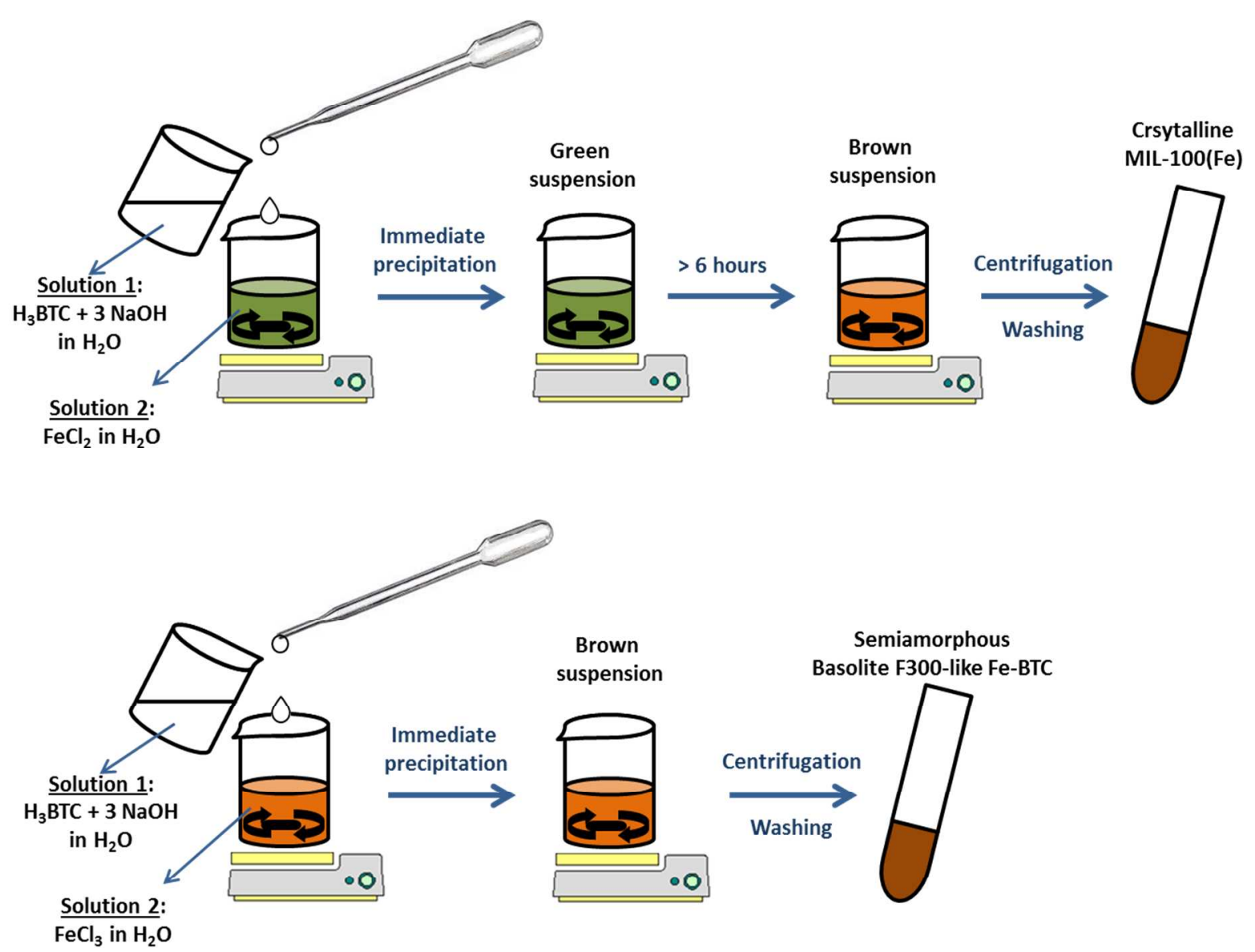

Scheme 1. Schematic representation of the sustainable synthesis procedures to prepare crystalline MIL-100(Fe) (top) and Basolite F300-like Fe-BTC (bottom) materials. 


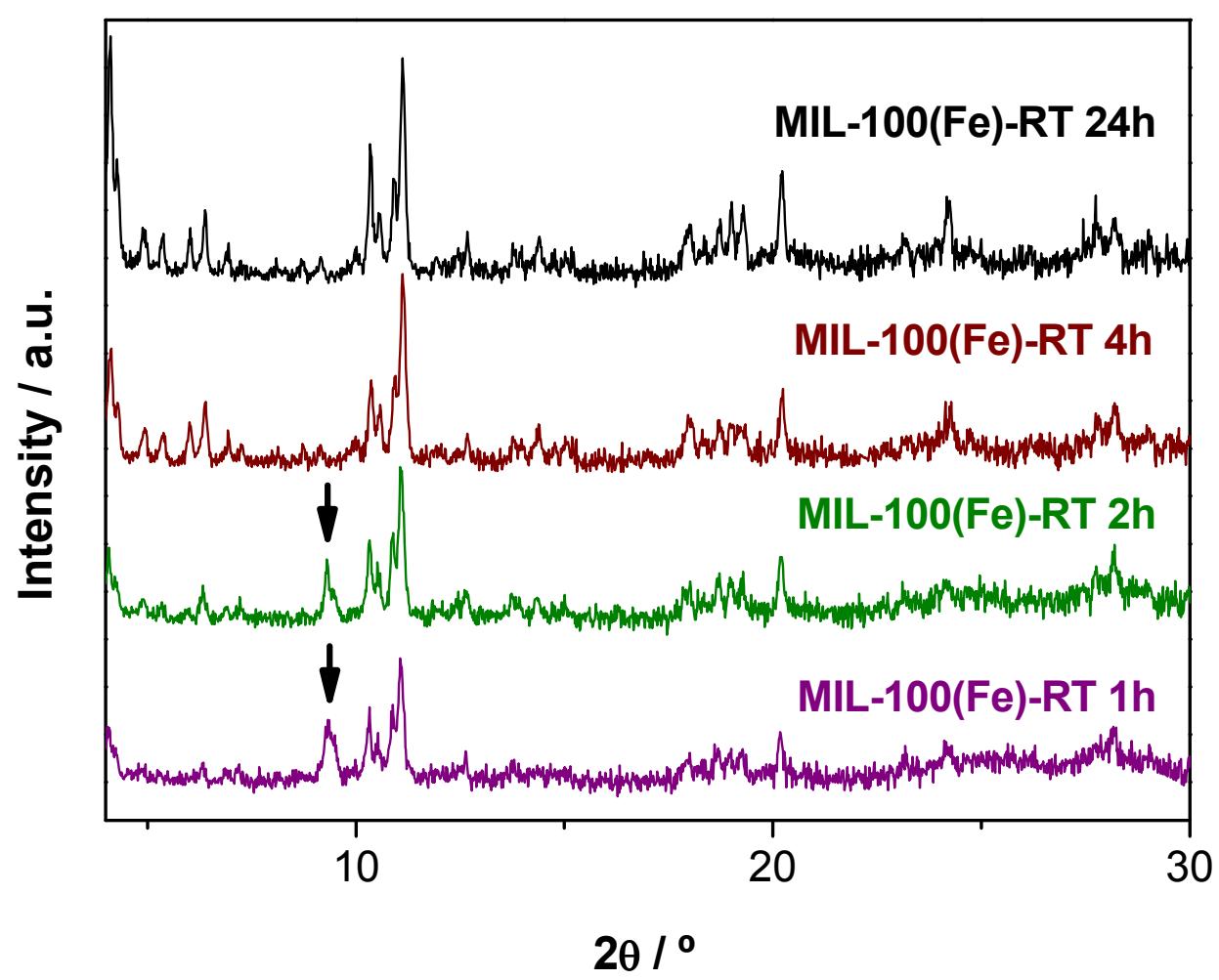

Figure 1. Powder XRD patterns of the MIL-100(Fe) samples extracted from the sustainable synthesis mixture after different reaction time. Arrows at $2 \theta$ near $10^{\circ}$ indicate the presence of XRD peaks that do not belong to the phase MIL-100(Fe). 

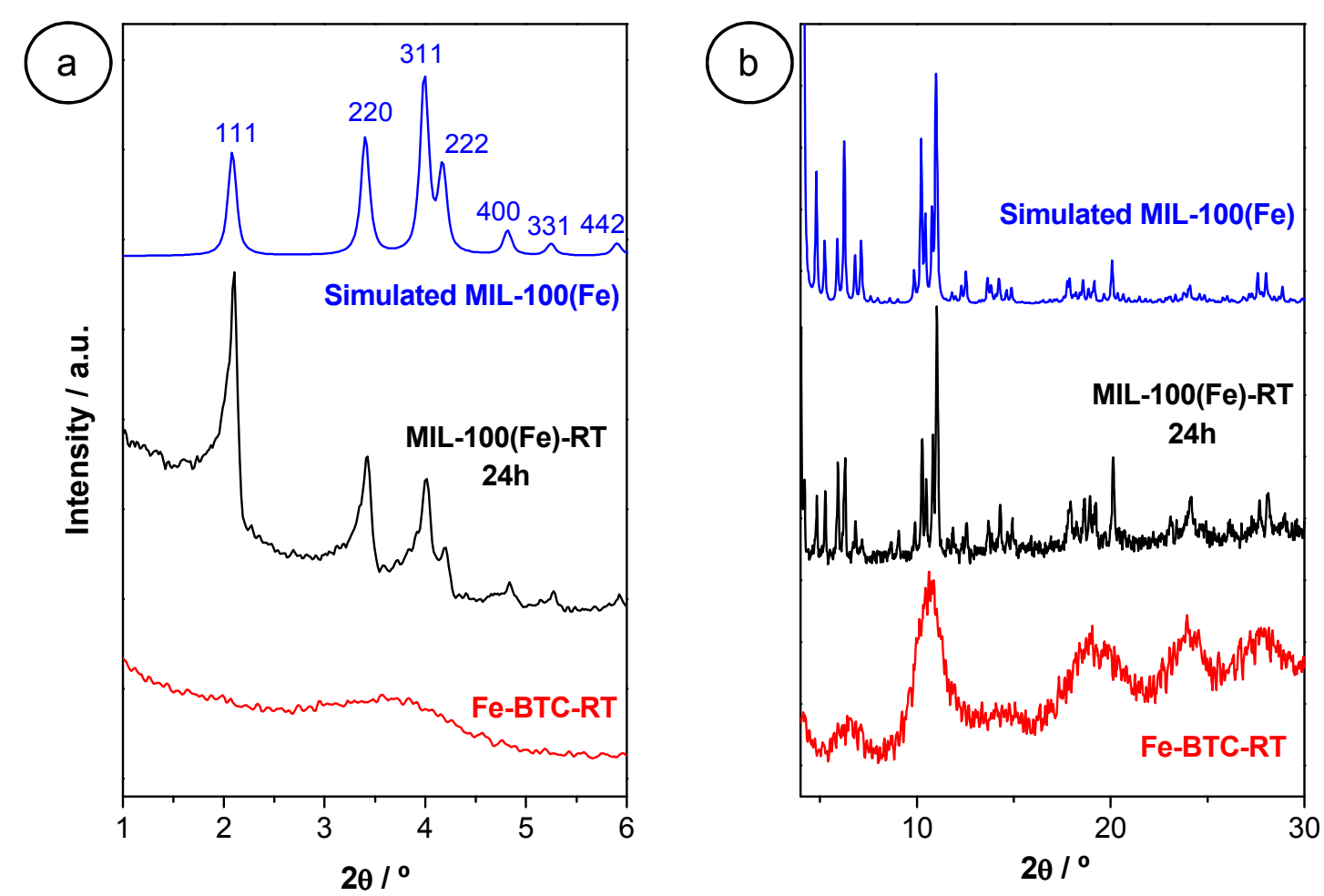

Figure 2. Experimental XRD patterns of the samples Fe-BTC-RT (red) and MIL-100(Fe)-RT after 24 hours (black) and the simulated XRD pattern of MIL-100(Fe) from the published CIF file (blue) in the low (a) and high (b) $2 \theta$ range. 

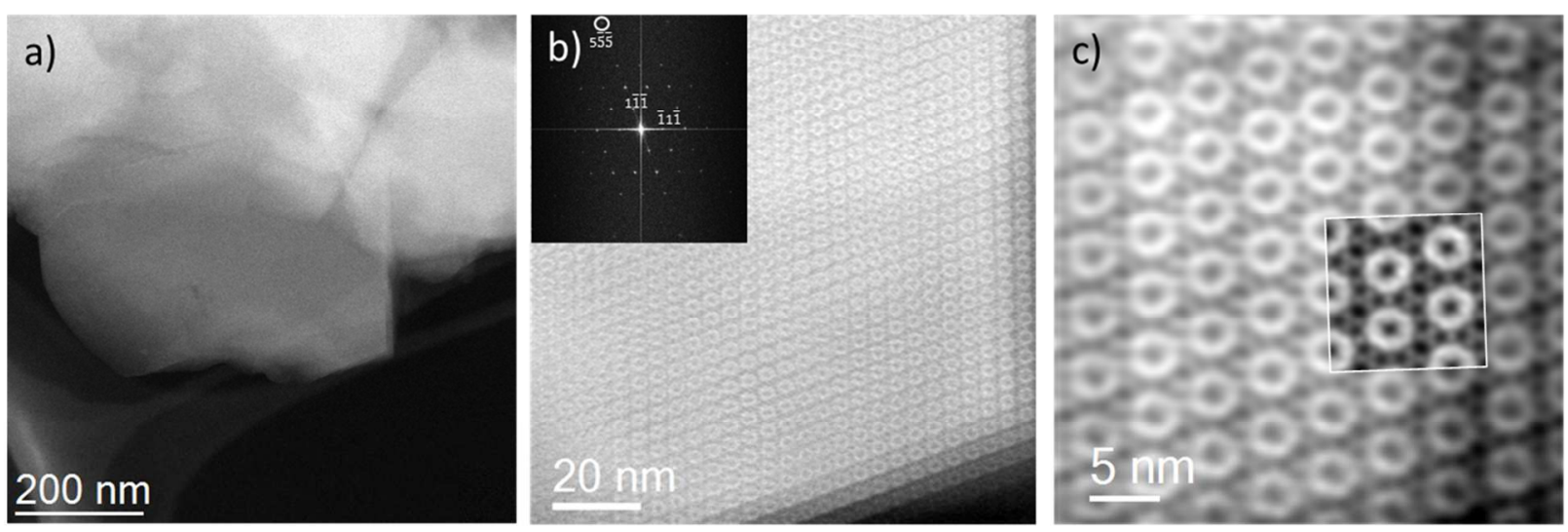

Figure 3. $\mathrm{C}_{\mathrm{s}}$-corrected STEM images of MIL-100(Fe)-RT, a) Low-magnification data of a 650 nm crystal. b) Closer inspection of the corner of that particle with the FFT inset. c) Fourier filtered data of figure $5 \mathrm{~b}$, which allows a clear visualization of the pore system. 


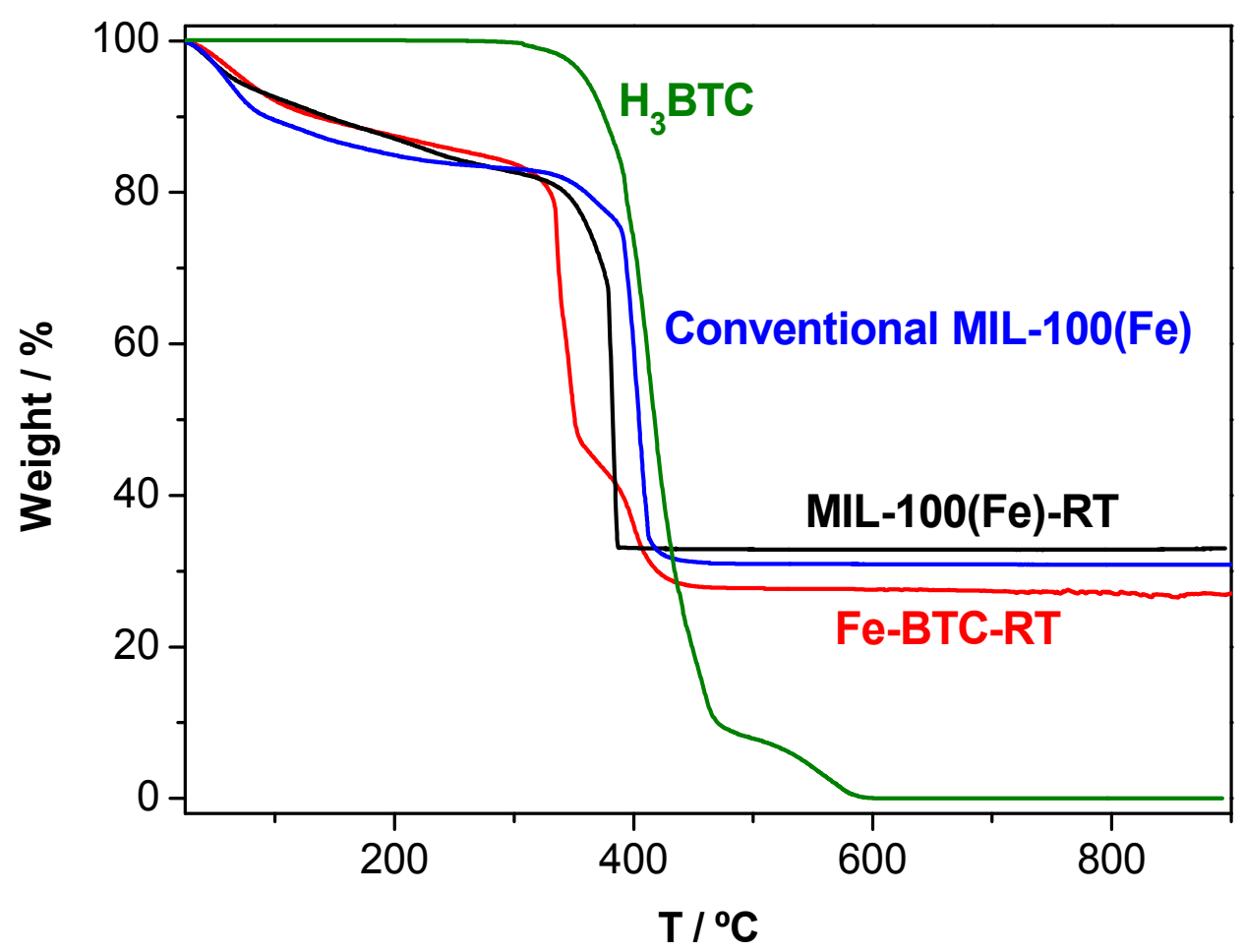

Figure 4. TGA plots of conventional MIL-100(Fe) (blue line), MIL-100(Fe)-RT (black) and Fe-BTC-RT (red).The TGA curve of the free linker $\mathrm{H}_{3} \mathrm{BTC}$ is also shown (green line). 

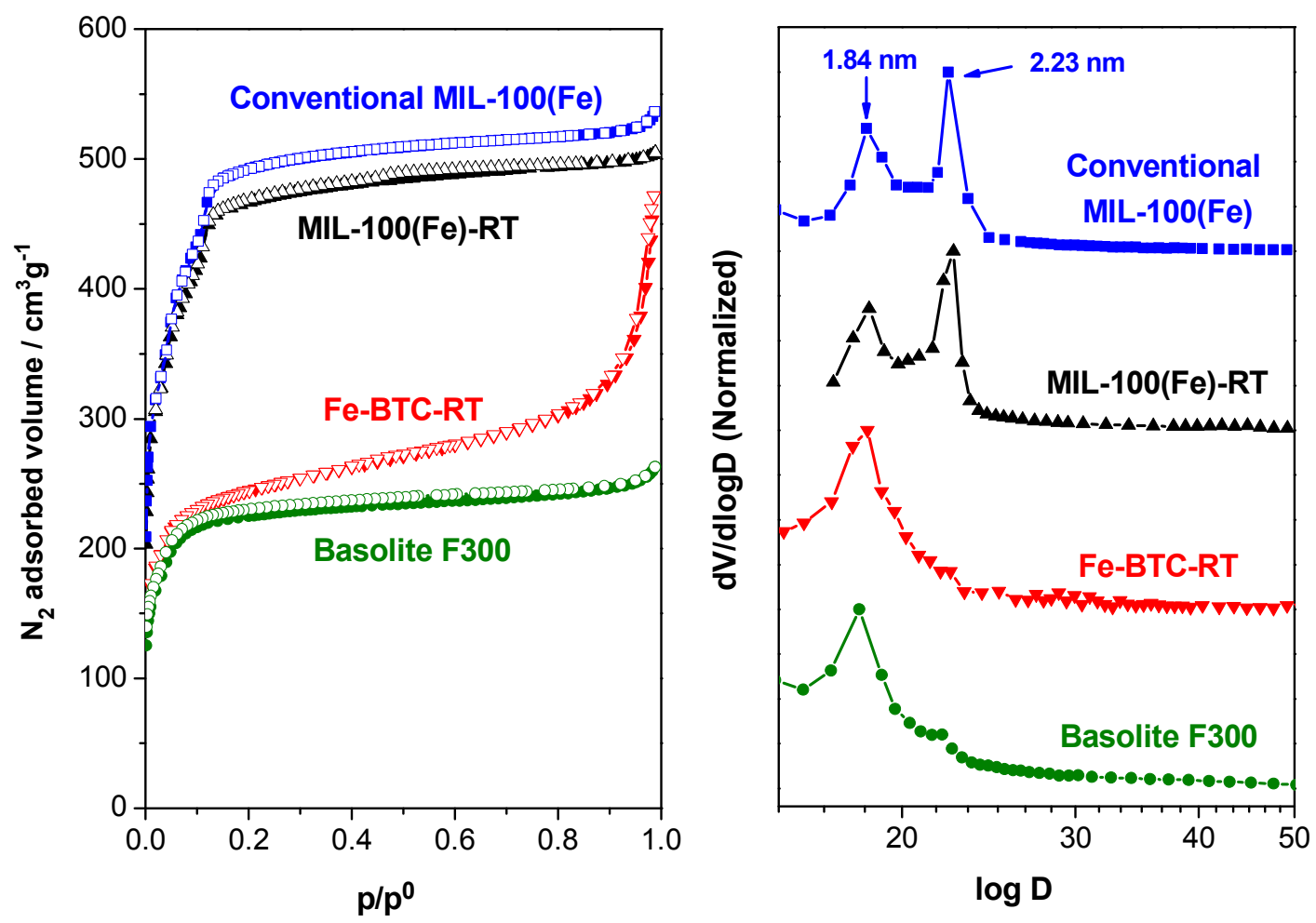

Figure 5. (a) $\mathrm{N}_{2}$ adsorption/desorption isotherms and (b) pore size distribution curves of the adsorption branches of the Fe-BTC samples: conventional MIL-100(Fe) (blue), MIL100(Fe)-RT (black) and Fe-BTC-RT (red), and commercial Basolite F-300 (green). Full and empty symbols represent adsorption and desorption experimental points, respectively. 


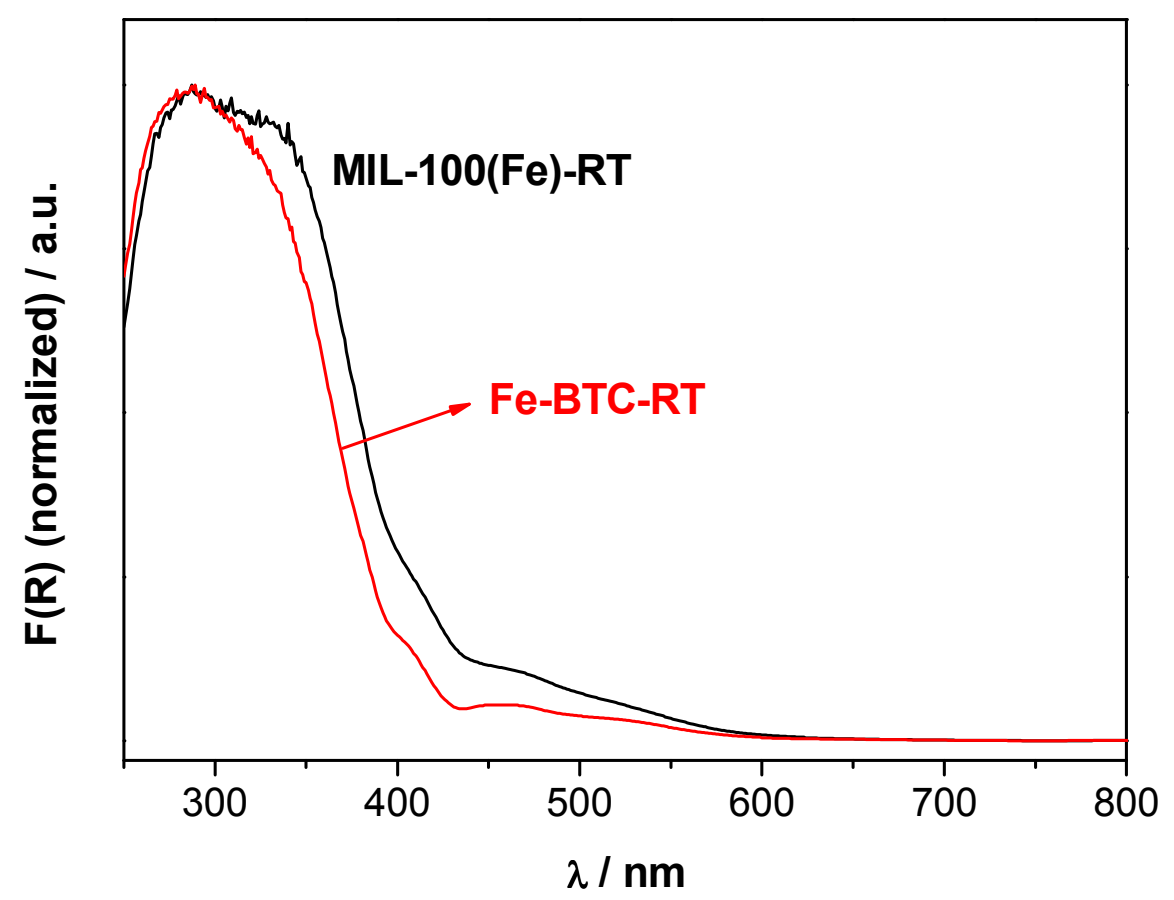

Figure 6. DR-UV-vis spectra of the samples MIL-100(Fe)-RT (black line) and Fe-BTC-RT (red line). The intensity has been normalized. 


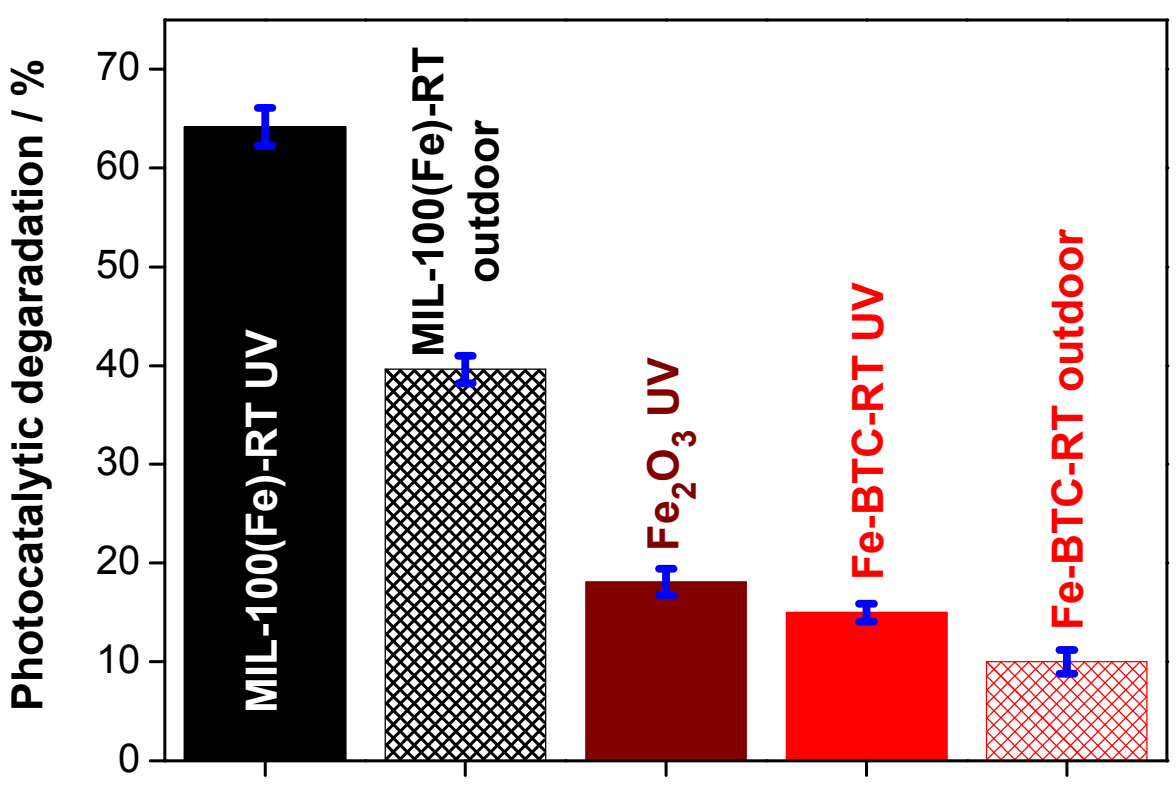

Photocatalysts

Figure 7. Photocatalytic degradation (\%) using the two different Fe-BTC photocatalysts prepared at room temperature (MIL-100(Fe)-RT in black, and Fe-BTC-RT in red) and different radiation (ultraviolet in solid columns, and outdoor sunlight in striped columns). Reaction conditions: $5 \mathrm{ppm}$ MO, $0.25 \mathrm{mg}$ of catalysts, reactor of $750 \mathrm{~mL}$. The photocatalytic degradation of $\mathrm{MO}$ with $\mathrm{Fe}_{2} \mathrm{O}_{3}$ under ultraviolet radiation (brown solid column) is also shown for comparison purposes. The blue segments indicate the error bar from two different measurements under similar conditions. 


\section{Supporting information}

Some extra material that includes Cs-corrected STEM images of the sample MIL-100(Fe)-RT and the graphical estimation of the band gap energy from DR-UV-vis spectra are given in Supporting Information. This material is available free of charge via the Internet at http://pubs.acs.org. 


\title{
FOR TABLE OF CONTENTS USE ONLY
}

\section{Sustainable preparation of MIL-100(Fe) and its photocatalytic degradation of methyl orange in water}

\author{
Kiros Guesh, Clarice A. D. Caiuby, Álvaro Mayoral, Manuel Díaz-García, Isabel Díaz and \\ Manuel Sánchez-Sánchez
}

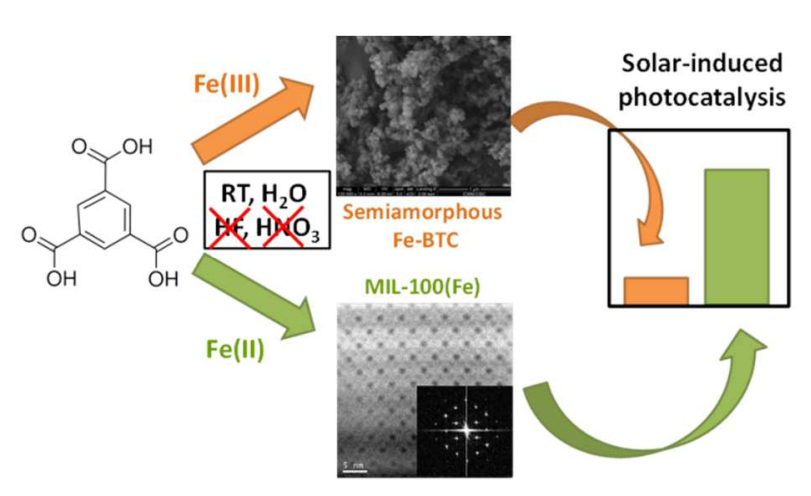

\section{SYNOPSYS}

This paper describes the most sustainable synthesis of MIL-100(Fe): at room temperature, in the absence of corrosive acids, at short times, etc. The same procedure leads to the semiamorphous Fe-BTC using Fe(III) sources or MIL-100(Fe) using Fe(II) ones. MIL-100(Fe) was much better photocatalyst in the degradation of methyl orange, because this dye cannot go through the windows of the former. 